\title{
An Extended Technology Acceptance Model for Mobile Social Gaming Service Popularity Analysis
}

\author{
Hui Chen, ${ }^{1,2}$ Wenge Rong, ${ }^{1,2}$ Xiaoyang $M a,{ }^{3}$ Yue $Q \mathbf{u},{ }^{2}$ and Zhang Xiong ${ }^{1,2}$ \\ ${ }^{1}$ State Key Laboratory of Software Development Environment, Beihang University, Beijing 100191, China \\ ${ }^{2}$ School of Computer Science and Engineering, Beihang University, Beijing 100191, China \\ ${ }^{3}$ Jacobs Institute, Cornell Tech, Cornell University, New York, NY, USA
}

Correspondence should be addressed to Wenge Rong; w.rong@buaa.edu.cn

Received 23 September 2016; Accepted 1 December 2016; Published 3 January 2017

Academic Editor: Qingchen Zhang

Copyright (C) 2017 Hui Chen et al. This is an open access article distributed under the Creative Commons Attribution License, which permits unrestricted use, distribution, and reproduction in any medium, provided the original work is properly cited.

\begin{abstract}
The games industry has been growing prosperously with the development of information technology. Recently, with further advances in social networks and mobile services, playing mobile social gaming has gradually changed our daily life in terms of social connection and leisure time spending. What are the determinant factors which affect users intention to play such games? Therefore in this research we present an empirical study on WeChat, China's most popular mobile social network, and apply a technology acceptance model (TAM) to study the reasons beneath the popularity of games in mobile social networks. Furthermore, factors from social and mobile perspective are incorporated into the conventional TAM and their influence and relationships are studied. Experimental study on accumulated online survey data reveals several interesting findings and it is believed that this research offers the researchers in the community further insight in analysing the current popularity and future potential of mobile social games.
\end{abstract}

\section{Introduction}

With the development of information technology, video games have become one of the most important applications and are wildly popular with all kinds of people of all ages. Playing video games has gradually changed people’s life style, particularly in terms of how leisure time is spent [1]. In addition, video games are also used to help people learn $[2,3]$, improve social skill [4], and even promote physical activity [5]. As an important video games platform, mobile devices, particularly smartphones, have become more and more popular. The increasing popularity of mobile devices is the key to open a huge market to mobile based gaming industry. For example, in China the mobile games players have increased to 279 million by early 2016 [6].

The smartphones provide a new platform for both social networking and video games. The mobile platform for social networks allows users to influence their friends [7] and have fun sharing their experiences [8]. Social networks have experienced exponential growth in recent years and with the further popularity of smartphones, mobile social network services will become one of the most popular applications due to their portability [9].

Due to the fact that playing games and using social networks are two of the most popular applications used daily on smartphones [10], it is worthwhile to investigate the integration of mobile social games. Currently playing games on mobile platform can have a lot of intentions, for example, education [11], while having fun in leisure time is a major purpose. In this research, we use games released on WeChat (Tencent's mobile social network service, known as Weixin (http://weixin.qq.com/) in China) as a case study to understand people's usage patterns and study what major determinants affect such games acceptance.

The WeChat App was first released in January 2011 as a mobile social network application which provides text, image, video, and voice messaging communication service. On 5th of August in 2013, Tencent released WeChat 5.0 which included a gaming centre. Several WeChat games were released with incredible numbers of games being downloaded. For example, a game called "Craz3 Match" was ranked 1st in App store just five hours after it was first released with more 
than 20 million downloads over the following three days. Subsequently many more games have been released which were also top ranked after their initial release.

Given the popularity of WeChat based games, we study in depth the reasons behind their broad acceptance. Many techniques in the literature can be used to analyse such behaviour patterns and technology acceptance model (TAM) [12] is one of the leading approaches. During the past decades, researchers have successfully applied TAM and/or its extended models to explain user acceptance of many information technology based systems [13-15]. In the TAM model, several determinant factors, for example, usefulness and ease of use, have been identified as key influences of adoption of new information systems [16].

Besides these fundamental factors, there are other variables which also contribute to the popularity of WeChat games. A lot of previous researches on user's intention of using social networks and/or playing mobile games have been conducted and can provide inspiration in social network based game analysis. For example, an extended TAM model was proposed by D.-H. Shin and Y.-J. Shin to investigate the factors affecting user's acceptance of social network games [17]. Lin and Lu created a model to explain why people use social networks by integrating network externalities and motivation theory [18]. Another study by Liang and Yeh focuses on the effect of use contexts on the intention of continuing to play mobile games [19]. As for the mobile social gaming, Park et al. analysed some determinants of player acceptance and paid much attention to entertainment, mobility, connectedness, and sociability [20].

In this research, we try to explain why people continue to play mobile social games and investigate the main determinants and their relationships. Specifically, this work proposes an extended TAM model and adds several additional variables, such as social interaction, enjoyment, and altruism to enhance the understanding of user's intention to play such games. The evaluation and validation of the proposed model are conducted by analysing questionnaires accumulated online and several interesting findings are revealed.

The remainder of this paper is organised as follows. In Section 2 we will introduce the background of the TAM model and mobile social gaming. Section 3 will present the proposed extended TAM model and list the objectives and hypotheses. In Section 4 we will present the collection, processing, and analysis of the data and discuss the experimental results. Finally Section 5 concludes the paper and outlines possible future work.

\section{Theoretical Foundations and Related Work}

2.1. Technology Acceptance Model. In the area of information systems, there is a need for researchers to understand the reasons behind the users' actual usage of IT systems. To solve this problem, many technologies have been proposed, for example, Theory of Reasoned Action (TRA) [21], Model of Personal Computer Utilisation (MPCU) [22], Motivational Model (MM) [23], Unified Theory of Acceptance and Use of Technology (UTAUT) [24], Theory of Planned Behaviour
(TPB) [25], and technology acceptance model (TAM) [12]. Of these approaches, technology acceptance model (TAM) has become one of the most popular and widely used techniques to elaborate on the rationality of users when they accept to use a certain information system. During the past decades, TAM has been successfully applied to lots of research domains and related applications and proven its capacity and validity in explaining user behaviour towards adoption of information systems.

In the earliest TAM model, it is argued that the actual system use is predicable by user motivation, which is also directly influenced by external variables, that is, system features, capabilities, and so on [12]. It is further suggested that user motivation consists of three influential factors, that is, perceived ease of use (PEOU), perceived usefulness (PU), and attitude towards using (ATT), which are able to explain the actual system use. In this TAM model, the attitude towards using, which is influenced by perceived usefulness (PU) and perceived ease of use (PEOU), is the major determinant for a user to accept or reject a certain system. Furthermore, perceived usefulness and perceived ease of use will be affected by several external stimuli. Davis finally hypothesised that perceived usefulness (PU) and perceived ease of use (PEOU) are the most important beliefs for a user to make a decision of whether to accept the system or not [12]. Since the TAM model was first proposed, it has been gradually refined and several other variables are added to the original TAM model, such as behavioural intention [16]. Because TAM has evolved into a leading model in predicting and explaining an information systems acceptance, it is believed the TAM model is also appropriate to analyse the popularity of mobile social gaming.

2.2. Mobile Social Gaming Analysis. Currently the video game has become one of the most important usages of advanced information technology. It has greatly transformed all people's behaviour pattern in spending their spare time [1], not only teenage but also elderly people [26]. Furthermore, with the development of the Internet, online multiplayer games are becoming more popular than single player games. As a result much effort has been devoted to understanding the popularity of online games. For example, Hsu and Lu tried to study the success of online games from the perspective of entertainment oriented technology and applied the TAM model by incorporating social influences and flow experience as belief-related constructs to predict the acceptance [27]. Lee argued that the flow experience is a more important factor than perceived enjoyment in influencing customers acceptance of online games [28] and further revealed that gender is a key moderator of online game acceptance. Later on Lee and Tsai proposed a theoretical research model, which integrates flow experience, human-computer interaction, social interaction, and perceived enjoyment, together with the technology acceptance model and Theory of Planned Behaviour to explain why people continue to play online games [29]. Wu and Liu suggested that trust is another important determinant for people continuing to play online games [30]. 
With the development of mobile devices, particularly the smartphone, playing online games in a mobile environment has become more and more popular as it extends the variance of place and time for users to play online games. According to the studies of $\mathrm{Liu}$ and $\mathrm{Li}$, the effect of use context on the formation of users perceptions of mobile services is powerful [31]. Liang and Yeh used TAM to analyse mobile game acceptance and demonstrate that the use context has a significant moderating effect on people's intention to play mobile games [19]. Ha et al. conducted research on wireless mobile broadband games and argued that both technological and psychological aspects are of importance for mobile game adoption [32], by extending TAM to include flow experience and attractiveness and measure the moderating effects of gender and age. Similarly, Petrova and Qu studied the adoption of mobile gaming in New Zealand's youth market and their findings proposed that the expressiveness is the most significant influential factor affecting intention to play mobile games [33].

Social networks, such as Facebook, Twitter, and WeChat, have greatly changed our daily life [34]. Kwon et al. gave a comparative analysis of user acceptance of Facebook and Twitter by extended TAM model to find the key motivation factors in using social network services [35]. Rosen and Sherman extended TAM model with flow experience to explain the acceptance of people's intention to use social networks [36]. Lin and $\mathrm{Lu}$ found that the most influential factor affecting users in joining social network services is enjoyment, followed by number of peers and usefulness [18]. Their findings further suggest that gender difference also has different influences. Sledgianowski and Kulviwat also argued that playfulness and critical mass are strongest indicators of intent to use social networking websites [37]. Kwon and Wen applied the TAM model to construct an amended model which revealed three individual differences, that is, social identity, altruism, and telepresence [38]. Rauniar et al. added the factors of users critical mass, social networking site capability, and trustworthiness to extend the TAM model and the results provided evidence for the importance of additional key variables to TAM in considering user engagement on social media sites and other social media related business strategies [39]. Similarly, Kim et al. found that the major motives for using social network sites are seeking friends, social support, entertainment, information, and convenience [40].

From the discussion above, it is clear that playing online games and surfing social network services are the two major mobile applications. It is found that social network games have been widely implemented further into mobile devise as applications [41]. It is then becoming very interesting to ask what if these two applications are combined together? Social aspects are also important for gaming, not only in console gaming [42], but also in games on social networks [43]. For example, players can buy and sell virtual goods in games via social networks [44]. D.-H. Shin and Y.-J. Shin proposed an extended TAM model to investigate factors influencing user acceptance of social games [17]. They found that perceived playfulness and security have significant effects on game adoption. Their findings also revealed that flow experience plays a moderate role which affects various paths in the model. Lin et al. proposed a model to examine the determining factors of playing social games [45]. Their findings demonstrate that a state of arousal leads people to a higher level of continuing to play social games. Recently, considering the popularity of mobile social games, Park et al. investigated some factors which affect the intentions of users to play such games, for example, control, skill, mobility, and connectedness [20]. They found that satisfaction has a significant effect with multiple connections in the research model. Similarly, in a study by Wei and Lu, both network externalities and individual gratification significantly influence the intention to play social games on mobile devices [46]. They also proposed some factors such as time flexibility, but they appear to be less significant according to their investigation. Similarly, Ding et al. conducted an empirical study of mobile social games and found that mobility, desire for advancement, relationship building, escapism, and high engagement motivate players to enter the game and have recreational play [47]

\section{Hypotheses}

Mobile social gaming is a new platform for people to play games with other friends. In this research we will use WeChat games as a case study to understand such attraction. To understand the popularity of a game platform, a large number of factors can be attached for importance; for example, people may concern about privacy in social game as users could use personal information to buy equipment. Such information stored in the app's cloud environment is sensitive [48]. In this research, we mainly studied the factors from social perspective; as such we proposed an extended TAM model including traditional factors such as perceived ease of use (PEU), perceived usefulness (PU), attitude (ATT), and behaviour intention (BI). Moreover, a game is different from a regular IT system because its main purpose is for entertainment, enjoyment, and relaxation [32]. As a result in the proposed model, we added external variables, that is, perceived enjoyment (PE), use context (UC), and flow experience (FL), to provide understanding of pleasure and fun, which are often mentioned in previous studies $[17,31,32]$. In addition, since mobile social gaming is also a kind of social platform for users to share fun and other experience, we also added social interaction (SI) and altruism (ALT) into the proposed model $[49,50]$. The research conceptual framework is depicted in Figure 1 and all variables and related hypotheses will be described in detail in the following subsections.

3.1. TAM. The proposed research model is an extension of the conventional TAM model. Therefore, the hypotheses of belief-attitude-intention-behaviour causal chain [21] is also adopted in the context of social based mobile games. Since games are entertainment oriented services, we use perceived ease of use (PEU) to represent how much effort a user thinks is needed to play a game. A high PEU score indicates that the game is easy to start playing and understand the 


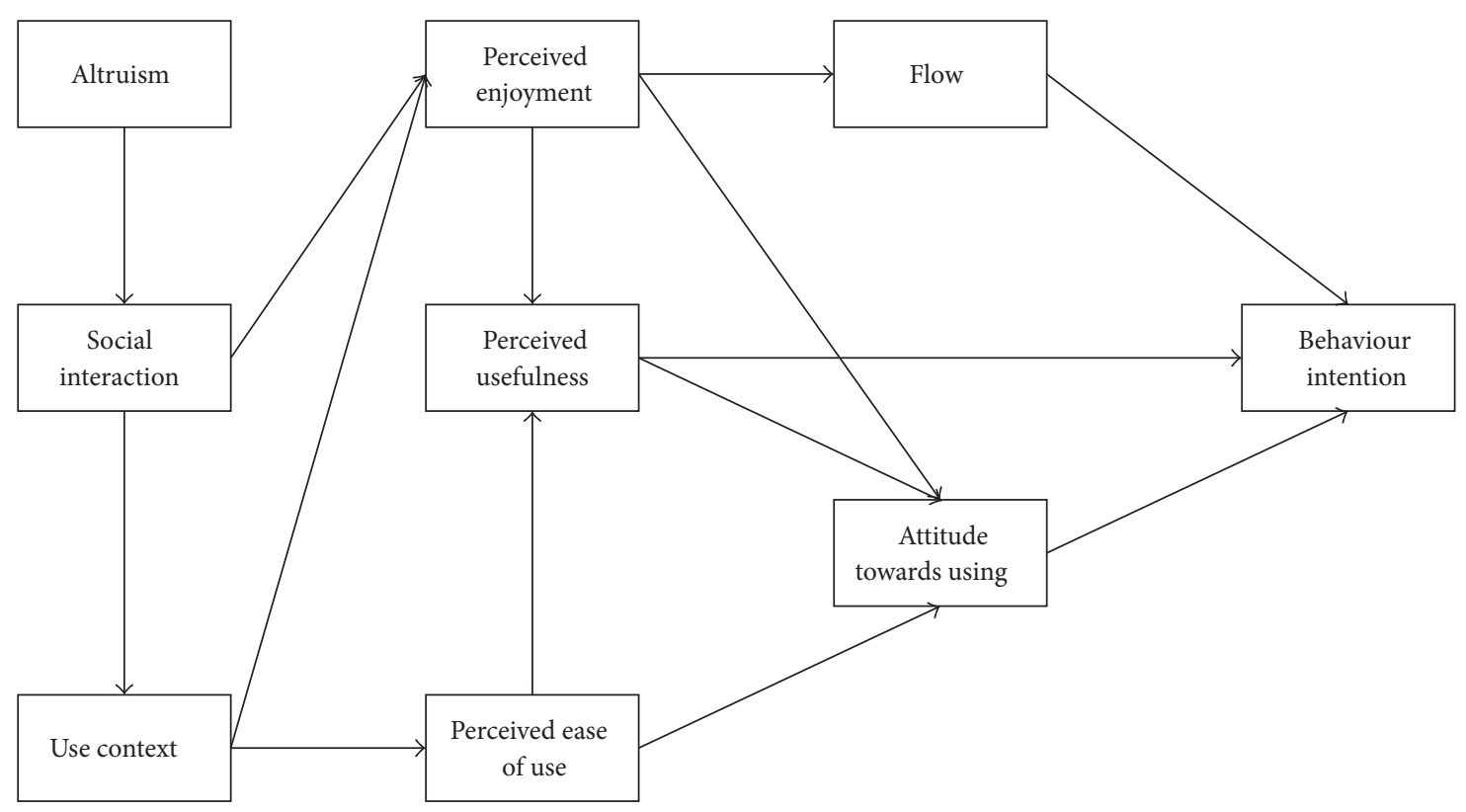

Figure 1: Proposed model.

rules. As a key structure in TAM, perceived usefulness (PU) has been refined and extended in various innovations [51], such as the improvement of job performance to measure innovation performance of "job/life/study" [31]. In this paper, we describe perceived usefulness as perceived improvement of the player's life experience caused by playing mobile social games. Consequently, we propose the following hypotheses:

(H1) Perceived ease of use (PEU) positively influences user's perceived usefulness (PU) of playing mobile social games.

(H2) Perceived ease of use (PEU) positively influences user's attitude (ATT) on social based mobile games.

(H3) Perceived usefulness (PU) positively influences user's attitude (ATT) on mobile social gaming.

(H4) Perceived usefulness (PU) positively influences user's intention (BI) to play mobile social games.

(H5) Attitude (ATT) positively influences user's intention (BI) to play mobile social games.

3.2. Perceived Enjoyment. Perceived enjoyment (PE) is the extent to which an activity is perceived to be enjoyable without considering any performance consequences [23]. It is an intrinsic motivation referring to the pleasure and satisfaction from performing a behaviour [52]. van der Heijden indicated that perceived enjoyment has a significant and positive influence on people's attitude and intention towards website adoption [53]. Moreover, in a study of the determinants of adoption of mobile games under mobile broadband wireless access environment, Ha et al. argued that perceived enjoyment should be one of the characteristics of games and perceived enjoyment should be included when analysing game systems [32]. Since social network based mobile gaming is also a kind of hedonic systems, we made the following hypotheses:

(H6) Perceived enjoyment (PE) positively influences attitude (ATT) on mobile social gaming.

(H7) Perceived enjoyment (PE) positively influences intention (FL) to play mobile social games.

(H8) Perceived enjoyment (PE) positively perceived usefulness (PU) of playing mobile social gaming.

3.3. Use Context. Use context (UC) refers to the environment where the technology will be used [54]. Use context is not just a point in time and space in which a particular action is taken. It also relates to situational and social contexts. Since smartphones have become a daily necessity in people's life, users may have a positive attitude towards a service when it fits a certain use context. Therefore, contextual factors should be added to traditional TAM model when studying user acceptance of mobile services. In fact, many previous studies have tried to integrate use context to extend the model. For example, in a study of exploring consumer adoption of mobile payments, Mallat pointed out that the adoption of mobile payment relies on certain situational factors such as a lack of other payment methods [55].

As many contextual factors may have great effect on user adoption, our study focuses on two factors which are highly related to mobile games, that is, the place where the people are and how the people feel at that time. For example, when people are in crowded public transportation and they feel bored, using a laptop is not possible but there is space to use a mobile phone. People can play mobile games to pass the time 
and enjoy themselves. Hence, two hypotheses are posited as follows:

(H9) Use context (UC) positively influences perceived enjoyment (PE) of mobile social gaming.

(H10) Use context (UC) positively influences perceived ease of use (PEU) to play mobile social games.

3.4. Flow. Flow (FL) was first put forward by M. Csikszentmihalyi and I. Csikszentmihalyi and defined as the holistic experience when involved in the action [56]. Due to the complexity and multidimensionality of flow [57], it has been extensively applied in a wide range of contexts, such as sports, shopping, rock climbing, dancing, and gaming [58]. Ghani argued that flow can be measured by enjoyment and concentration and found that perceived control and challenges can predict flow [59]. In subsequent studies, Li and Browne further explained flow with four dimensions: focused attention, control, curiosity, and temporal dissociation [60]. In this study, the concept of flow focuses on curiosity. Curiosity refers to the situation that people stay curious about the system and try to accomplish technological competence while being engaged in an action [14]. In Moon and Kim's study, users remain curious about the Internet because they can acquire new information and knowledge. As for mobile social gaming, people can not only play games but also compete and share with their friends. These above remain the curiosity of the players and lead to the replay intention. Consequently, we have the following hypothesis:

(H11) Flow (FL) positively influences intention (BI) to play mobile social gaming.

3.5. Social Interaction. Interaction is a kind of behaviour between two or more objects. In prior studies interaction is usually classified into two types. The first is the interaction between the user and the system, and the second is user-touser interaction [61]. In this study, since we focus on mobile social networks, we focus on user-to-user interaction which is usually called social interaction (SI). Social games are built to be enjoyed and shared with friends through existing social networks and platforms. In WeChat, people play games on the same platform which allows them to share scores and compete with each other. Furthermore, people can give lives as present to friends, which causes closer relationship. Those above really bring much fun and therefore we propose the following hypotheses:

(H12) Social interaction (SI) positively influences perceived enjoyment (PE) of mobile social gaming.

(H13) Social interaction (SI) positively influences use context (UC) of mobile social gaming.

3.6. Altruism. Altruism (AL) can be classified into kin altruism and reciprocal altruism [38]. Kin altruism refers to concept that people sacrifice their own benefits to help their genetic relatives, and reciprocal altruism means that people help others because they believe that they will receive similar assistance in return some day in the future [62]. It
TABLE 1: Design of the questionnaire.

\begin{tabular}{lccc}
\hline Factor & Abbreviation & $\begin{array}{c}\text { Question } \\
\text { number }\end{array}$ & $\begin{array}{c}\text { Verification } \\
\text { questions } \\
\text { (Y/N) }\end{array}$ \\
\hline Social interaction & SI & 3 & $\mathrm{~N}$ \\
Altruism & ALT & 3 & $\mathrm{~N}$ \\
Perceived enjoyment & $\mathrm{PE}$ & 4 & $\mathrm{Y}$ \\
Perceived usefulness & $\mathrm{PU}$ & 3 & $\mathrm{~N}$ \\
Perceived ease of use & PEU & 3 & $\mathrm{Y}$ \\
Flow & $\mathrm{FL}$ & 3 & $\mathrm{~N}$ \\
Attitude & ATT & 3 & $\mathrm{~N}$ \\
Use context & $\mathrm{UC}$ & 3 & $\mathrm{~N}$ \\
Behaviour intention & $\mathrm{BI}$ & 3 & $\mathrm{~N}$ \\
\hline
\end{tabular}

is interesting that users display both kinds of altruism in mobile social gaming. In the popular WeChat game "Aircraft Wars," people can give their own lives to friends as a present and this is also popular in other WeChat games. However, altruism is an alternative to explain the people's behaviour [63]. It is difficult to understand the altruistic behaviour from the traditional economic view that people behave to maximise their own preferences [45]. Considering that TAM is an extension of the Theory of Reasoned Action (TRA), it is not suitable to apply altruism to traditional TAM framework [64]. We should add a new perceived construct to explain the altruistic behaviour. In the context of mobile social gaming, the altruistic behaviour may be more motivated by the perceived enjoyment of the players due to the friendship between them. Hence, our hypothesis on altruism is stated as follows:

(H14) Altruism (ALT) positively influences social interaction (SI) of mobile social gaming.

\section{Results and Analysis}

4.1. Data Collection. In this research we published questionnaires on an online survey agency to collect the experimental data. The original questionnaire consists of two parts. The first part has 8 questions to collect the basic information of the informants, such as sex, age, and use experience with WeChat and/or games. The second part is the main component of the questionnaire and consists of 32 questions to investigate the 9 factors introduced in previous section. Each question is measured on a 7-point Likert scale with the end points of "strongly agree (7)" and "strongly disagree (1)".

The data collection process uses a two-step approach. Firstly we conducted a pilot test to verify the questionnaire's accuracy, which results in the removal of 4 questions from the original questionnaire. As a result the final questionnaire consists of 28 questions, among which two questions are designed as reverse questions to help judge insincere responses. Table 1 lists the final published questionnaire, and the 26 questions (without the two reverse questions) are listed in Table 2. 
TABLE 2: Questionnaire.

\begin{tabular}{|c|c|c|}
\hline Factor & Item & Measure \\
\hline \multirow{3}{*}{ Social interaction (SI) } & SI1 & I like to play the game which my friends play. \\
\hline & SI2 & WeChat games provide a platform for me to play games with my friends. \\
\hline & SI3 & I like to play games with friends. \\
\hline \multirow{3}{*}{ Altruism (ALT) } & ALT1 & I will give my friends gifts or other in-game help. \\
\hline & ALT2 & I often help my friends when they need help in WeChat games. \\
\hline & ALT3 & My friends often give me feedback when I offer help they need in WeChat games. \\
\hline \multirow{3}{*}{ Perceived enjoyment (PE) } & PE1 & It is interesting to play WeChat games. \\
\hline & PE2 & Playing WeChat games brings enjoyment to my daily life. \\
\hline & PE3 & I always feel happy when I am playing WeChat games. \\
\hline \multirow{3}{*}{ Perceived usefulness (PU) } & PU1 & Playing WeChat games makes my life different. \\
\hline & PU2 & Playing WeChat games makes my life better. \\
\hline & PU3 & Playing WeChat games is useful for me. \\
\hline \multirow{2}{*}{ Perceived ease of use (PEU) } & PEU1 & It is easy for me to play WeChat games. \\
\hline & PEU2 & It is easy for me to master the rules of the games. \\
\hline \multirow{3}{*}{ Flow (FL) } & FL1 & I will not be tired of WeChat games in a short time. \\
\hline & FL2 & I will not lose interest in WeChat games in a short time. \\
\hline & FL3 & It happened often for me to ignore the time past when I play WeChat games. \\
\hline \multirow{3}{*}{ Attitude (ATT) } & ATT1 & It is a good idea for me to play WeChat games during my free time. \\
\hline & ATT2 & I feel good towards WeChat games. \\
\hline & ATT3 & I like playing WeChat games. \\
\hline \multirow{3}{*}{ Use context (UC) } & $\mathrm{UC1}$ & Playing WeChat games is a way to spend free time for me. \\
\hline & UC2 & I will consider to play WeChat games when I am bored. \\
\hline & UC3 & I will consider to play WeChat games when I have free time. \\
\hline \multirow{3}{*}{ Behaviour intention (BI) } & BI1 & I want to play more kinds of WeChat games later. \\
\hline & $\mathrm{BI} 2$ & I will keep playing WeChat games. \\
\hline & $\mathrm{BI} 3$ & I will play WeChat games with my friends together. \\
\hline
\end{tabular}

TABLE 3: Data filtering result.

\begin{tabular}{lc}
\hline Item & Number \\
\hline Total responses & 491 \\
Not played WeChat games & 122 \\
Insincere response & 61 \\
Effective responses & 308 \\
\hline
\end{tabular}

A total of 491 responses were collected from the online survey. In order to improve the quality of the data we filter out responses which fit the following criteria: (1) Eliminate the responses of respondents who have never played a WeChat game. (2) Eliminate the insincere responses through data filtering on the two verification questions. (3) Eliminate the insincere responses which look like "Straight-Line" or "Wave" [65]. The final result is as shown in Table 3. In the field of human-computer interaction for qualitative analysis, the size of the data set containing more than 200 valid responses can be viewed as an effective data set [51]. In this experiment, we collected 308 valid questionnaire responses so we regard this as an effective data set.

\subsection{Data Analysis}

4.2.1. Reliability Analysis. In order to analyse the effectiveness of the original data, the first step of the experiment is to conduct data standardisation. In this step we calculate the average and standard deviation of each question result and also the average for each category. The results are shown in Table 4 . From the table we can see that the average of all factors is greater than 5 , which suggests that the assumptive factors were typical.

Afterwards we further employ Cronbach's alpha coefficient to show the convergent validity and internal reliability of the factors, which are listed in Table 5. From Table 5 we can see that the total Cronbach's alpha coefficient is 0.947 and the coefficients of each factor are greater than 0.7. It is then argued that the total Cronbach's alpha coefficient is acceptable $(>0.8$ [66]), and the coefficients of each factor are also acceptable $(>0.7[66])$. As a result we conclude that the data are reliable measures for their factors.

Meanwhile, discriminant validity is verified as to ensure that variables relate more strongly to their own factor than to other factors. As shown in Table 6, the maximum correlations between different factors are below 0.70 [32]. Therefore it is 
TABLE 4: Question standardisation and reliability analysis.

\begin{tabular}{|c|c|c|c|c|}
\hline Factor & Question & AVG & $\mathrm{SD}$ & AVG \\
\hline \multirow{3}{*}{ SI } & SI1 & 5.98 & 0.943 & \multirow{3}{*}{5.88} \\
\hline & SI2 & 5.86 & 1.040 & \\
\hline & SI3 & 5.81 & 1.085 & \\
\hline \multirow{3}{*}{ ALT } & ALT1 & 5.94 & 1.003 & \multirow{3}{*}{5.92} \\
\hline & ALT2 & 5.97 & 0.920 & \\
\hline & ALT3 & 5.87 & 0.947 & \\
\hline \multirow{3}{*}{ PE } & PE1 & 5.87 & 0.989 & \multirow{3}{*}{5.84} \\
\hline & PE2 & 5.86 & 0.909 & \\
\hline & PE3 & 5.80 & 0.958 & \\
\hline \multirow{3}{*}{$\mathrm{PU}$} & PU1 & 5.36 & 1.220 & \multirow{3}{*}{5.37} \\
\hline & PU2 & 5.41 & 1.153 & \\
\hline & PU3 & 5.36 & 1.305 & \\
\hline \multirow{2}{*}{ PEU } & PEU1 & 5.93 & 0.773 & \multirow{2}{*}{5.98} \\
\hline & PEU2 & 6.03 & 0.786 & \\
\hline \multirow{3}{*}{$\mathrm{FL}$} & FL1 & 5.32 & 1.265 & \multirow{3}{*}{5.44} \\
\hline & FL2 & 5.50 & 1.035 & \\
\hline & FL3 & 5.51 & 1.163 & \\
\hline \multirow{3}{*}{ ATT } & ATT1 & 5.87 & 0.946 & \multirow{3}{*}{5.84} \\
\hline & ATT2 & 5.85 & 0.939 & \\
\hline & ATT3 & 5.79 & 0.929 & \\
\hline \multirow{3}{*}{ UC } & $\mathrm{UC1}$ & 6.04 & 0.855 & \multirow{3}{*}{5.99} \\
\hline & UC2 & 6.01 & 0.941 & \\
\hline & UC3 & 5.92 & 0.963 & \\
\hline \multirow{3}{*}{ BI } & BI1 & 5.98 & 0.950 & \multirow{3}{*}{5.94} \\
\hline & $\mathrm{BI} 2$ & 6.05 & 0.910 & \\
\hline & $\mathrm{BI} 3$ & 5.80 & 1.080 & \\
\hline
\end{tabular}

able to conclude that the factors are sufficiently distinct and uncorrelated.

4.2.2. Principal Component Analysis. The next step of data analysis is to conduct principal component analysis (PCA). Before that, it is necessary to test the adequacy of data. In this research, KMO Testing and Bartlett Testing are employed to validate whether the data are suitable for PCA process [67]. The result is shown in Table 7. As suggested by commonly used KMO measures, it is concluded that our collected data are appropriate for principal component analysis. After the PCA process, the next step is to rotate the matrix from PCA analysis to distinguish the importance of the 9 factors. The result is shown in Table 8 and it is seen that the importance rank of the 9 factors, from high to low, is PU, ATT, SI, ALT, PE, UC, FL, BI, and PEU, respectively.

\subsection{Hypothesis Evaluation}

4.3.1. Model Fit Indices. To evaluate the proposed model and validate the proposed hypotheses, eight fit indices are employed in this research, that is, $X^{2}$, GFI, AGFI, RMSEA,
TABLE 5: Cronbach's alpha coefficient of each factor.

\begin{tabular}{lc}
\hline Factor & Cronbach's alpha coefficient \\
\hline SI & 0.789 \\
ALT & 0.776 \\
PE & 0.799 \\
PU & 0.872 \\
PEU & 0.718 \\
FL & 0.749 \\
ATT & 0.786 \\
UC & 0.727 \\
BI & 0.735 \\
Total (26 questions) & 0.947 \\
\hline
\end{tabular}

RMR, CFI, NFI, and IFI [68]. The fitness results for the measurement are shown in Table 9 and each of the fitness measures is acceptable. Consequently, all the measures chosen in this work appear to show that the proposed model can provide a good fit to the data, thereby making it possible to conduct path analysis for the proposed model.

4.3.2. Path Analysis. The aim of path analysis is to evaluate the veracity and reliability of the hypothetical model and measure the strength of the causal relationship between variables. We examined the structural equation model by testing the hypothesised relationships between various factors, as shown in Figure 2 and Table 10.

4.4. Discussion. This study developed a theoretical framework and discussed the structural equation modelling analysis of the proposed theoretical framework for mobile social game adoption. Consistent with previous studies focusing on online games and mobile social network services [17, 20, 4547], our findings in this study provided empirical support for the proposed TAM extended model. The results clarified our understanding of people's attitudes and intentions towards playing mobile social games and also helped to reveal implications for the successful implementation of WeChat games in China. The measurement of this study provided a good fit to the data, thereby lending support to the proposed model. Overall, the results show that the proposed model is able to accurately describe the intentions of users to play mobile social games.

From this study it is found that perceived enjoyment and perceived ease of use are the chief determinants of user attitudes to play mobile social games. This may suggest that (1) players regard the level of enjoyment from playing mobile social games as the most significant factor and (2) players prefer to play some easier to get started mobile social games which would not cost them much effort. Of these two factors, perceived enjoyment shows a much stronger effect than perceived ease of use, which implies that entertainment oriented technologies will be paid much attention by the markets. Furthermore, this model shows insignificant role of perceived usefulness, which sharply contrasts perceived enjoyment and perceived ease of use, in affecting user attitude to play mobile social games. From this research it is concluded 
TABLE 6: Intercorrelations between factors.

\begin{tabular}{|c|c|c|c|c|c|c|c|c|c|}
\hline & SI & ALT & $\mathrm{PE}$ & PU & PEU & FL & ATT & UC & $\mathrm{BI}$ \\
\hline SI & 1.000 & & & & & & & & \\
\hline ALT & 0.612 & 1.000 & & & & & & & \\
\hline $\mathrm{PE}$ & 0.637 & 0.492 & 1.000 & & & & & & \\
\hline PU & 0.527 & 0.470 & 0.417 & 1.000 & & & & & \\
\hline PEU & 0.530 & 0.479 & 0.562 & 0.292 & 1.000 & & & & \\
\hline FL & 0.651 & 0.509 & 0.631 & 0.621 & 0.494 & 1.000 & & & \\
\hline ATT & 0.563 & 0.452 & 0.475 & 0.602 & 0.379 & 0.598 & 1.000 & & \\
\hline UC & 0.657 & 0.508 & 0.618 & 0.568 & 0.518 & 0.687 & 0.638 & 1.000 & \\
\hline BI & 0.695 & 0.556 & 0.674 & 0.603 & 0.541 & 0.673 & 0.600 & 0.699 & 1.000 \\
\hline
\end{tabular}

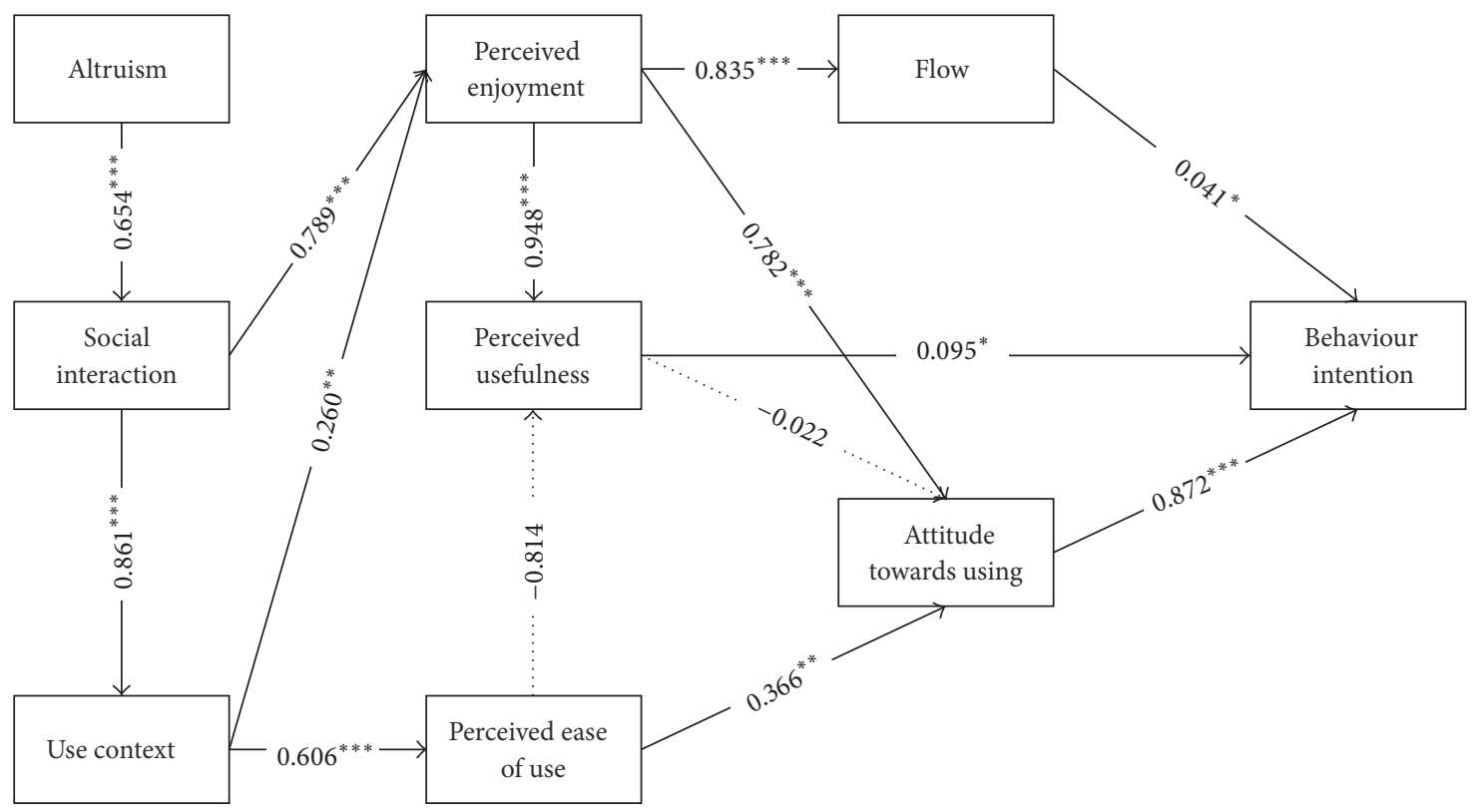

Figure 2: Path verification. ${ }^{*} p<0.05,{ }^{* *} p<0.01,{ }^{* * *} p<0.001$.

TABLE 7: KMO and Bartlett Testing.

\begin{tabular}{lc}
\hline Kaiser-Meyer-Olkin & .942 \\
\hline Bartlett Testing & \\
$X^{2}$ & 4518.333 \\
df & 325 \\
Sig. & .000 \\
\hline
\end{tabular}

that perceived usefulness also does not have very strong effect on the actual behaviour intention, which corroborates previous studies $[17,27]$ that perceived usefulness may have an insignificant effect on user attitude. Therefore combining our findings with other existing works in the literature, it may be inferred that, in the domain of mobile social games, users mainly want to easily get fun from social games as a hedonic system in mobile environment anytime and anywhere without considering too many performance consequences.
Considering the importance and the significance of perceived enjoyment, it is deserved to conduct further investigation to study the relationship between it with other factors. From this research, it is reasonable to argue that enjoyment can enhance perception of flow. In fact, the popularity of some WeChat games is partly because of its mechanism of making fun from keeping playing to beat friends. However, due to the fact that normally users play WeChat games to kill the boring time, for example, when using public transportation, it is not surprising to see that flow does not exert significant effect on the intention.

Our findings also shows that social interaction does have strong influence on perceived enjoyment while it also has significant influence on use context. Mobile social games provide a new platform for users to communicate with each other and then close the relationship among them. For example, in WeChat games, users can compete against, offer help to, and/or interact promptly with their friends, thereby making the gaming more interesting. In this research, it is also found that social interaction in WeChat games is also supported by altruism. Offering help in the games does bring 
TABLE 8: Rotation matrix.

\begin{tabular}{|c|c|c|c|c|c|c|c|c|c|}
\hline & \multicolumn{9}{|c|}{ Component } \\
\hline & 1 & 2 & 3 & 4 & 5 & 6 & 7 & 8 & 9 \\
\hline SI1 & 0.106 & 0.339 & 0.578 & 0.246 & 0.129 & 0.322 & 0.086 & 0.037 & 0.149 \\
\hline SI2 & 0.227 & 0.151 & 0.713 & 0.212 & 0.196 & 0.040 & 0.195 & 0.189 & 0.074 \\
\hline SI3 & 0.190 & 0.167 & 0.766 & 0.129 & 0.199 & 0.152 & 0.080 & 0.083 & 0.070 \\
\hline ALT1 & 0.227 & 0.104 & 0.189 & 0.689 & -0.019 & 0.125 & 0.213 & 0.340 & 0.114 \\
\hline ALT2 & 0.043 & 0.165 & 0.114 & 0.755 & 0.198 & 0.310 & 0.071 & -0.066 & 0.023 \\
\hline ALT3 & 0.211 & 0.106 & 0.171 & 0.770 & 0.180 & -0.026 & -0.034 & 0.105 & 0.183 \\
\hline PE1 & 0.279 & 0.322 & 0.320 & 0.096 & 0.483 & 0.108 & 0.207 & 0.400 & -0.005 \\
\hline PE2 & 0.255 & 0.188 & 0.237 & 0.145 & 0.707 & 0.200 & 0.191 & 0.023 & 0.120 \\
\hline PE3 & 0.232 & 0.175 & 0.219 & 0.230 & 0.598 & 0.092 & 0.086 & 0.174 & 0.266 \\
\hline PU1 & 0.767 & 0.183 & 0.222 & 0.103 & 0.096 & -0.005 & 0.243 & 0.302 & -0.009 \\
\hline PU2 & 0.778 & 0.226 & 0.118 & 0.115 & 0.309 & 0.134 & 0.130 & -0.009 & -0.010 \\
\hline PU3 & 0.826 & 0.118 & 0.168 & 0.211 & 0.136 & 0.128 & 0.102 & 0.031 & 0.146 \\
\hline PEU1 & 0.108 & 0.037 & 0.079 & 0.090 & 0.222 & 0.201 & 0.128 & 0.048 & 0.840 \\
\hline PEU2 & -0.034 & 0.401 & 0.160 & 0.296 & 0.050 & 0.157 & -0.011 & 0.225 & 0.613 \\
\hline FL1 & 0.176 & 0.117 & 0.135 & 0.072 & 0.127 & 0.019 & 0.843 & 0.260 & 0.021 \\
\hline FL2 & 0.253 & 0.281 & 0.133 & 0.089 & 0.196 & 0.221 & 0.730 & -0.154 & 0.163 \\
\hline FL3 & 0.383 & 0.262 & 0.192 & 0.307 & -0.077 & 0.132 & 0.571 & 0.038 & 0.116 \\
\hline ATT1 & 0.130 & 0.505 & 0.121 & 0.163 & 0.398 & 0.163 & 0.177 & 0.485 & 0.125 \\
\hline ATT2 & 0.209 & 0.669 & 0.216 & 0.024 & 0.288 & 0.016 & 0.284 & 0.067 & 0.075 \\
\hline ATT3 & 0.199 & 0.589 & 0.195 & 0.239 & 0.315 & 0.209 & 0.004 & 0.156 & 0.134 \\
\hline $\mathrm{UC1}$ & 0.080 & 0.362 & 0.176 & 0.133 & 0.454 & 0.504 & 0.122 & 0.021 & 0.228 \\
\hline UC2 & 0.074 & 0.117 & 0.013 & 0.206 & 0.133 & 0.751 & 0.151 & 0.233 & 0.151 \\
\hline UC3 & 0.148 & 0.116 & 0.387 & 0.053 & 0.152 & 0.656 & -0.001 & 0.101 & 0.140 \\
\hline BI1 & 0.235 & 0.366 & 0.238 & 0.136 & 0.308 & 0.312 & 0.220 & 0.410 & 0.112 \\
\hline $\mathrm{BI} 2$ & 0.107 & 0.064 & 0.175 & 0.181 & 0.065 & 0.457 & 0.046 & 0.664 & 0.195 \\
\hline $\mathrm{BI} 3$ & 0.349 & 0.061 & 0.343 & 0.118 & 0.312 & 0.243 & 0.140 & 0.488 & 0.093 \\
\hline
\end{tabular}

TABLE 9: Fit indices for the measurement.

\begin{tabular}{lcc}
\hline & Results & Recommended criteria \\
\hline$X^{2}$ & 1.844 & $<5.0$ \\
GFI & 0.886 & $>0.85$, close to 1 \\
AGFI & 0.854 & $>0.80$, close to 1 \\
RMSEA & 0.052 & $\leq 0.06$, close to 0 \\
RMR & 0.043 & $\leq 0.08$, close to 0 \\
CFI & 0.947 & $>0.90$, close to 1 \\
NFI & 0.892 & $>0.85$, close to 1 \\
IFI & 0.947 & $>0.90$, close to 1 \\
\hline
\end{tabular}

a lot of fun and social reputation among friends. As such it suggests that social interaction plays a key role in increasing the enjoyment, thereby increasing the user attitude to play WeChat games.

Meanwhile, since users can use WeChat to communicate with each other when they have spare time, it is easier for a user to realise other friends' activity in WeChat games with portable smartphones. The use context for easily accessing and playing mobile social games by social connection does provide more chance for users to get involved into WeChat games, which is also the major cause of WeChat games
TABLE 10: Analysis of significance of path coefficient.

\begin{tabular}{lcc}
\hline Hypothesis & Estimate & Supported? \\
\hline$(\mathrm{H} 1) \mathrm{PEU} \rightarrow \mathrm{PU}$ & -0.814 & $\mathrm{~N}$ \\
$(\mathrm{H} 2) \mathrm{PEU} \rightarrow \mathrm{ATT}$ & $0.366^{* *}$ & $\mathrm{Y}$ \\
$(\mathrm{H} 3) \mathrm{PU} \rightarrow \mathrm{ATT}$ & -0.022 & $\mathrm{~N}$ \\
$(\mathrm{H} 4) \mathrm{PU} \rightarrow \mathrm{BI}$ & $0.095^{*}$ & $\mathrm{Y}$ \\
$(\mathrm{H} 5) \mathrm{ATT} \rightarrow \mathrm{BI}$ & $0.872^{* * *}$ & $\mathrm{Y}$ \\
$(\mathrm{H} 6) \mathrm{PE} \rightarrow \mathrm{ATT}$ & $0.782^{* * *}$ & $\mathrm{Y}$ \\
$(\mathrm{H} 7) \mathrm{PE} \rightarrow \mathrm{FL}$ & $0.835^{* * *}$ & $\mathrm{Y}$ \\
$(\mathrm{H} 8) \mathrm{PE} \rightarrow \mathrm{PU}$ & $0.948^{* * *}$ & $\mathrm{Y}$ \\
$(\mathrm{H} 9) \mathrm{UC} \rightarrow \mathrm{PE}$ & $0.260^{* *}$ & $\mathrm{Y}$ \\
$(\mathrm{H} 10) \mathrm{UC} \rightarrow \mathrm{PEU}$ & $0.606^{* * *}$ & $\mathrm{Y}$ \\
$(\mathrm{H} 11) \mathrm{FL} \rightarrow \mathrm{BI}$ & $0.041^{*}$ & $\mathrm{Y}$ \\
$(\mathrm{H} 12) \mathrm{SI} \rightarrow \mathrm{PE}$ & $0.789^{* * *}$ & $\mathrm{Y}$ \\
$(\mathrm{H} 13) \mathrm{SI} \rightarrow \mathrm{UC}$ & $0.861^{* * *}$ & $\mathrm{Y}$ \\
$(\mathrm{H} 14) \mathrm{ALT} \rightarrow \mathrm{SI}$ & $0.654^{* * *}$ & $\mathrm{Y}$ \\
\hline
\end{tabular}

${ }^{*} p<0.05,{ }^{* *} p<0.01,{ }^{* * *} p<0.001$.

spreading. This result supports previous research on use context $[19,31,69]$. Due to the fact that mobile social games have low requirement on network environment, hard devices, 
and storage space, it is easy for people to play anytime and anywhere.

This proposed extended TAM model has several practical and theoretical implications for researchers and engineers to develop popular mobile social games. This study provided some in-depth analysis of popularity of WeChat games in China and then can be applied into development of games industry. It is argued that successful mobile social games should exert significant efforts to deliver enjoyable games in an easily accessible way as well as to provide excellent social interaction experience to encourage users to share their fun.

\section{Conclusion and Future Work}

Nowadays along with the development of social network service and mobile devices, social network based mobile gaming has become wildly popular. In this research we provide a use case analysis of the factors affecting acceptance of mobile social games on WeChat. To this end, we employ a technology acceptance model and integrate some amending predictors from social and mobile perspective. Our analysis of over 300 valid questionnaire respondents provides revealing findings on the influence of 9 factors on the acceptance of mobile social games. We believe that this research provides invaluable insight for mobile social game service providers, enabling better understanding of adoption behaviour and thus further improving their services.

Similar to other researches, there are several limitations in this study which deserve future effort to address. The major issue is related to the users of WeChat. The questionnaire in this research is in Chinese and all responses are from Mainland China. Furthermore, WeChat is not the only service for the social network though it is the most popular one in China indeed. Using WeChat as case study in this paper does provide some interesting findings; however, the results may be not easy to generalise. It would be interesting to extend this work into an international context and perhaps consider other social networks.

In contrast with other studies, there may be some important factors which may significantly contribute to the integrated model and deserve to be further investigated. For example, considering the possibility for WeChat games to involve payment and advertisement in terms of virtual gift, it can be forecast that user's comprehensive sense of security would have significant influence on user attitudes towards to mobile social games, thereby making perceived security an essential factor for further study. Furthermore, continuous usage of mobile games is also important as attracting users to use a game is a challenge but keeping the users to play with games is another even more challenging task. Therefore, analysis of factors for mobile game's continuous usage deserves to be studied further in the future research.

\section{Competing Interests}

The authors declare that there is no conflict of interests regarding the publication of this paper.

\section{Acknowledgments}

This work was supported by the State Key Laboratory of Software Development Environment of China (no. SKLSDE2015ZX-23), the National Natural Science Foundation of China (no. 61472021), and the Fundamental Research Funds for the Central Universities.

\section{References}

[1] T. M. Connolly, E. A. Boyle, E. MacArthur, T. Hainey, and J. M. Boyle, "A systematic literature review of empirical evidence on computer games and serious games," Computers \& Education, vol. 59, no. 2, pp. 661-686, 2012.

[2] M. Papastergiou, "Digital game-based learning in high school computer science education: impact on educational effectiveness and student motivation," Computers \& Education, vol. 52, no. 1, pp. 1-12, 2009.

[3] G.-J. Hwang and P.-H. Wu, "Advancements and trends in digital game-based learning research: a review of publications in selected journals from 2001 to 2010," British Journal of Educational Technology, vol. 43, no. 1, pp. E6-E10, 2012.

[4] A. M. Piper, E. O’Brien, M. R. Morris, and T. Winograd, "SIDES: a cooperative tabletop computer game for social skills development," in Proceedings of the ACM Conference on Computer Supported Cooperative Work, pp. 1-10, 2006.

[5] A. Barnett, E. Cerin, and T. Baranowski, "Active video games for youth: a systematic review," Journal of Physical Activity and Health, vol. 8, no. 5, pp. 724-737, 2011.

[6] CNNIC, "35th statistical report on Internet development in China," 2016, https://cnnic.com.cn/IDR/ReportDownloads/ 201604/P020160419390562421055.pdf.

[7] C. López-Nicolás, F. J. Molina-Castillo, and H. Bouwman, "An assessment of advanced mobile services acceptance: contributions from TAM and diffusion theory models," Information of Management, vol. 45, no. 6, pp. 359-364, 2008.

[8] D. M. Boyd and N. B. Ellison, "Social network sites: definition, history, and scholarship," Journal of Computer-Mediated Communication, vol. 13, no. 1, pp. 210-230, 2007.

[9] S. Nikou and H. Bouwman, "Ubiquitous use of mobile social network services," Telematics and Informatics, vol. 31, no. 3, pp. 422-433, 2014.

[10] PwC, "Mobile advertising in China: what do Chinese consumers want and how should businesses be engaging with them?" 2014, http://www.pwccn.com/webmedia/doc/ 635358539404587393_mobile_ad_china_cut_may2014.pdf.

[11] G. Schwabe and C. Göth, "Mobile learning with a mobile game: design and motivational effects," Journal of Computer Assisted Learning, vol. 21, no. 3, pp. 204-216, 2005.

[12] F. D. Davis, "Perceived usefulness, perceived ease of use, and user acceptance of information technology," MIS Quarterly, vol. 13, no. 3, pp. 319-340, 1989.

[13] J. C.-C. Lin and H. Lu, "Towards an understanding of the behavioural intention to use a web site," International Journal of Information Management, vol. 20, no. 3, pp. 197-208, 2000.

[14] J.-W. Moon and Y.-G. Kim, "Extending the TAM for a worldwide-web context," Information \& Management, vol. 38, no. 4, pp. 217-230, 2001.

[15] M. Koufaris, "Applying the technology acceptance model and flow theory to online consumer behavior," Information Systems Research, vol. 13, no. 2, pp. 205-223, 2002. 
[16] F. D. Davis, R. P. Bagozzi, and P. R. Warshaw, "User acceptance of computer technology: a comparison of two theoretical models," Management Science, vol. 35, no. 8, pp. 982-1003, 1989.

[17] D.-H. Shin and Y.-J. Shin, "Why do people play social network games?" Computers in Human Behavior, vol. 27, no. 2, pp. 852861, 2011.

[18] K.-Y. Lin and H.-P. Lu, "Why people use social networking sites: an empirical study integrating network externalities and motivation theory," Computers in Human Behavior, vol. 27, no. 3, pp. 1152-1161, 2011.

[19] T.-P. Liang and Y.-H. Yeh, "Effect of use contexts on the continuous use of mobile services: the case of mobile games," Personal and Ubiquitous Computing, vol. 15, no. 2, pp. 187-196, 2011.

[20] E. Park, S. Baek, J. Ohm, and H. J. Chang, "Determinants of player acceptance of mobile social network games: an application of extended technology acceptance model," Telematics and Informatics, vol. 31, no. 1, pp. 3-15, 2014.

[21] M. Fishbein and I. Ajzen, Belief, Attitude, Intention, and Behavior: An Introduction to Theory and Research, Addison-Wesley, 1975.

[22] R. L. Thompson, C. A. Higgins, and J. M. Howell, "Personal computing: toward a conceptual model of utilization," MIS Quarterly, vol. 15, no. 1, pp. 125-143, 1991.

[23] F. D. Davis, R. P. Bagozzi, and P. R. Warshaw, "Extrinsic and intrinsic motivation to use computers in the workplace," Journal of Applied Social Psychology, vol. 22, no. 14, pp. 1111-1132, 1992.

[24] V. Venkatesh, M. G. Morris, G. B. Davis, and F. D. Davis, "User acceptance of information technology: toward a unified view," MIS Quarterly, vol. 27, no. 3, pp. 425-478, 2003.

[25] I. Ajzen, "The theory of planned behavior," Organizational Behavior and Human Decision Processes, vol. 50, no. 2, pp. 179211, 1991.

[26] Q. Wang and X. Sun, "Investigating gameplay intention of the elderly using an extended technology acceptance model (ETAM)," Technological Forecasting and Social Change, vol. 107, pp. 59-68, 2016.

[27] C.-L. Hsu and H.-P. Lu, "Why do people play on-line games? An extended TAM with social influences and flow experience," Information \& Management, vol. 41, no. 7, pp. 853-868, 2004.

[28] M.-C. Lee, "Understanding the behavioural intention to play online games: an extension of the theory of planned behaviour," Online Information Review, vol. 33, no. 5, pp. 849-872, 2009.

[29] M. Lee and T. Tsai, "What drives people to continue to play online games? An extension of technology model and theory of planned behavior," International Journal of Human-Computer Interaction, vol. 26, no. 6, pp. 601-620, 2010.

[30] J. Wu and D. Liu, "The effects of trust and enjoyment on intention to play online games," Journal of Electronic Commerce Research, vol. 8, no. 2, pp. 128-140, 2007.

[31] Y. Liu and H. Li, "Exploring the impact of use context on mobile hedonic services adoption: an empirical study on mobile gaming in China," Computers in Human Behavior, vol. 27, no. 2, pp. 890-898, 2011.

[32] I. Ha, Y. Yoon, and M. Choi, "Determinants of adoption of mobile games under mobile broadband wireless access environment," Information \& Management, vol. 44, no. 3, pp. 276-286, 2007.

[33] K. Petrova and H. Qu, "Playing mobile games: consumer perceptions: an empirical study," in Proceedings of the International Conference on e-Business, pp. 209-214, 2007.
[34] K.-Y. Lin and H.-P. Lu, "Predicting mobile social network acceptance based on mobile value and social influence," Internet Research, vol. 25, no. 1, pp. 107-130, 2015.

[35] S. J. Kwon, E. Park, and K. J. Kim, "What drives successful social networking services? A comparative analysis of user acceptance of Facebook and Twitter," The Social Science Journal, vol. 51, no. 4, pp. 534-544, 2014.

[36] P. Rosen and P. Sherman, "Hedonic information systems: acceptance of social networking websites," in Proceedings of the 12th Americas Conference on Information Systems, p. 162, Acapulco, Mexico, August 2006.

[37] D. Sledgianowski and S. Kulviwat, "Social network sites: antecedents of user adoption and usage," in Proceedings of the 14th Americas Conference on Information Systems, p. 83, Toronto, Canada, August 2008.

[38] O. Kwon and Y. Wen, "An empirical study of the factors affecting social network service use," Computers in Human Behavior, vol. 26, no. 2, pp. 254-263, 2010.

[39] R. Rauniar, G. Rawski, J. Yang, and B. Johnson, “Technology acceptance model (TAM) and social media usage: an empirical study on Facebook," Journal of Enterprise Information Management, vol. 27, no. 1, pp. 6-30, 2014.

[40] Y. Kim, D. Sohn, and S. M. Choi, "Cultural difference in motivations for using social network sites: a comparative study of American and Korean college students," Computers in Human Behavior, vol. 27, no. 1, pp. 365-372, 2011.

[41] C. Feijoo, J.-L. Gómez-Barroso, J.-M. Aguado, and S. Ramos, "Mobile gaming: industry challenges and policy implications," Telecommunications Policy, vol. 36, no. 3, pp. 212-221, 2012.

[42] A. Voida and S. Greenberg, "Wii all play: the console game as a computational meeting place," in Proceedings of the 27th International Conference on Human Factors in Computing Systems, pp. 1559-1568, Boston, Mass, USA, April 2009.

[43] J. Kim, Y. Chang, and M. Park, "Why do people like to play social network games with their friends? A focus on sociability and playability," in Proceedings of the 17th Pacific Asia Conference on Information Systems, p. 78, 2013.

[44] J. Hamari and L. Keronen, "Why do people buy virtual goods? A literature review," in Proceedings of the 49th Hawaii International Conference on System Sciences, pp. 1358-1367, Koloa, Hawaii, USA, January 2016.

[45] T. Lin, H. Lu, H. Hsu, S. Hsing, and T. Ho, "Why do people continue to play social network game (SNG)? An empirical study by social and emotional perspectives," International Journal of E-Adoption, vol. 5, no. 4, pp. 22-35, 2013.

[46] P.-S. Wei and H.-P. Lu, "Why do people play mobile social games? An examination of network externalities and of uses and gratifications," Internet Research, vol. 24, no. 3, pp. 313-331, 2014.

[47] Y. Ding, Y. Zhou, and A. Kankanhalli, "Why do I invite friends to join: an empirical study of mobile social network game," in Proceedings of the 18th Pacific Asia Conference on Information Systems, p. 137, June 2014.

[48] Q. Zhang, L. T. Yang, and Z. Chen, "Privacy preserving deep computation model on cloud for big data feature learning," IEEE Transactions on Computers, vol. 65, no. 5, pp. 1351-1362, 2016.

[49] S. Trepte, L. Reinecke, and K. Juechems, "The social side of gaming: how playing online computer games creates online and offline social support," Computers in Human Behavior, vol. 28, no. 3, pp. 832-839, 2012. 
[50] O. Curry, S. G. B. Roberts, and R. I. M. Dunbar, "Altruism in social networks: evidence for a 'kinship premium," British Journal of Psychology, vol. 104, no. 2, pp. 283-295, 2013.

[51] P. Legris, J. Ingham, and P. Collerette, "Why do people use information technology? A critical review of the technology acceptance model," Information \& Management, vol. 40, no. 3, pp. 191-204, 2003.

[52] J. Doll and I. Ajzen, "Accessibility and stability of predictors in the theory of planned behavior," Journal of Personality and Social Psychology, vol. 63, no. 5, pp. 754-765, 1992.

[53] H. van der Heijden, "Factors influencing the usage of websites: the case of a generic portal in The Netherlands," Information \& Management, vol. 40, no. 6, pp. 541-549, 2003.

[54] L. van de Wijngaert and H. Bouwman, "Would you share? Predicting the potential use of a new technology," Telematics and Informatics, vol. 26, no. 1, pp. 85-102, 2009.

[55] N. Mallat, "Exploring consumer adoption of mobile payments-a qualitative study," The Journal of Strategic Information Systems, vol. 16, no. 4, pp. 413-432, 2007.

[56] M. Csikszentmihalyi and I. Csikszentmihalyi, Optimal Experience: Psychological Studies of Flow in Consciousness, Cambridge University Press, 2000.

[57] Y. Lu, T. Zhou, and B. Wang, "Exploring Chinese users' acceptance of instant messaging using the theory of planned behavior, the technology acceptance model, and the flow theory," Computers in Human Behavior, vol. 25, no. 1, pp. 2939, 2009.

[58] M. Csikszentmihalyi and J. LeFevre, "Optimal experience in work and leisure," Journal of Personality and Social Psychology, vol. 56, no. 5, pp. 815-822, 1989.

[59] J. A. Ghani, "Human factors in information systems," in Flow in Human-Computer Interactions: Test of a Model, J. M. Carey, Ed., pp. 291-311, Ablex, 1995.

[60] D. Li and G. J. Browne, "The role of need for cognition and mood in online flow experience," Journal of Computer Information Systems, vol. 46, no. 3, pp. 11-17, 2006.

[61] D. Choi and J. Kim, "Why people continue to play online games: in search of critical design factors to increase customer loyalty to online contents," CyberPsychology \& Behavior, vol. 7, no. 1, pp. 11-24, 2004.

[62] M. C. Ashton, S. V. Paunonen, E. Helmes, and D. N. Jackson, "Kin altruism, reciprocal altruism, and the big five personality factors," Evolution and Human Behavior, vol. 19, no. 4, pp. 243255,1998

[63] H. Rachlin, "Altruism and selfishness," Behavioral and Brain Sciences, vol. 25, no. 2, pp. 239-250, 2002.

[64] N. Folbre and R. E. Goodin, "Revealing altruism," Review of Social Economy, vol. 62, no. 1, pp. 1-25, 2004.

[65] S. H. Burton, R. G. Morris, C. G. Giraud-Carrier, J. H. West, and R. Thackeray, "Mining useful association rules from questionnaire data," Intelligent Data Analysis, vol. 18, no. 3, pp. 479-494, 2014.

[66] Y. Hong and Y. Li, "The research on index system optimization of graduation design based on cronbach coefficient," in Proceedings of the 5th International Conference on Computer Science and Education, pp. 1843-1845, Hefei, China, August 2010.

[67] B. Williams, A. Onsman, and T. Brown, "Exploratory factor analysis: a five-step guide for novices," Australasian Journal of Paramedicine, vol. 8, no. 3, 2010.
[68] C.-L. Hsu and H.-P. Lu, "Consumer behavior in online game communities: a motivational factor perspective," Computers in Human Behavior, vol. 23, no. 3, pp. 1642-1659, 2007.

[69] H. van der Heijden, M. Ogertschnig, and L. van der Gaast, "Effects of context relevance and perceived risk on user acceptance of mobile information services," in Proceedings of the 13th European Conference on Information Systems, pp. 286-296, 2005. 

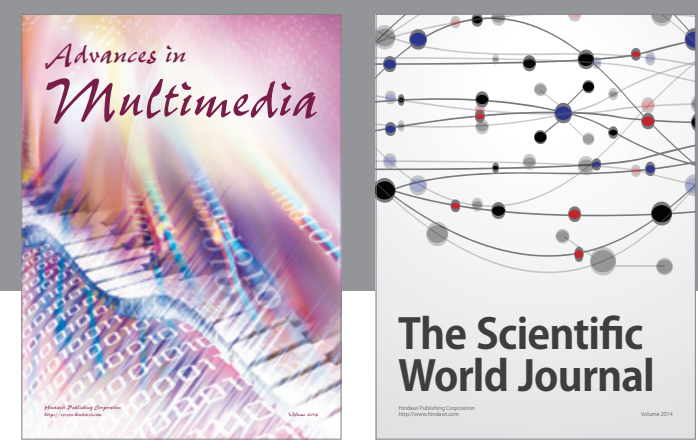

The Scientific World Journal
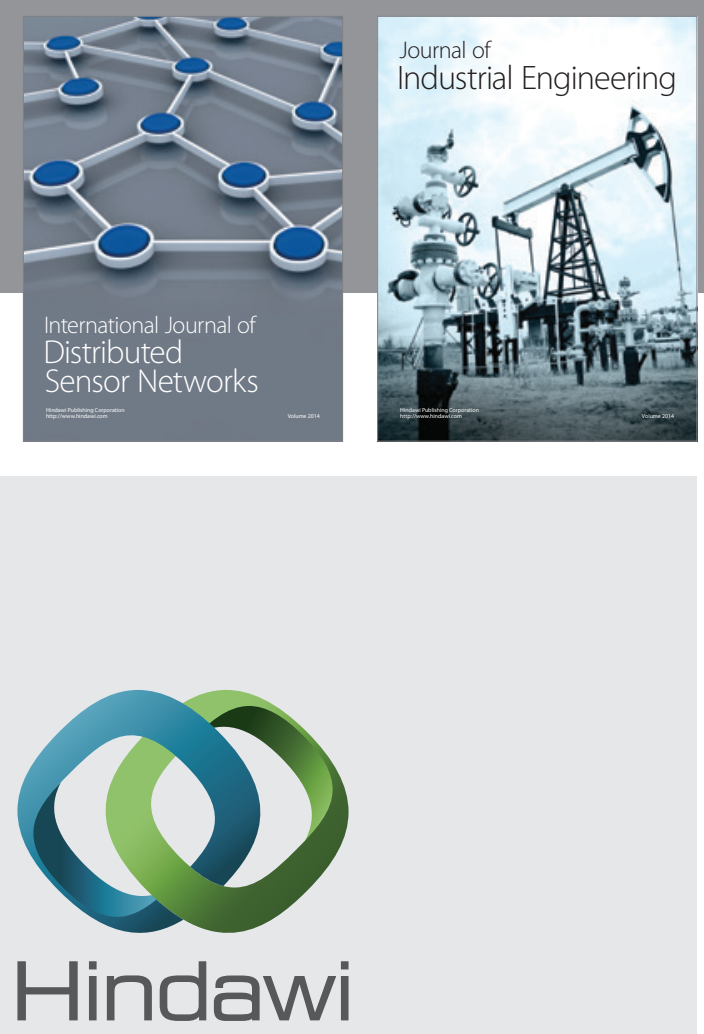

Submit your manuscripts at

https://www.hindawi.com

\section{Computer Networks} and Communications
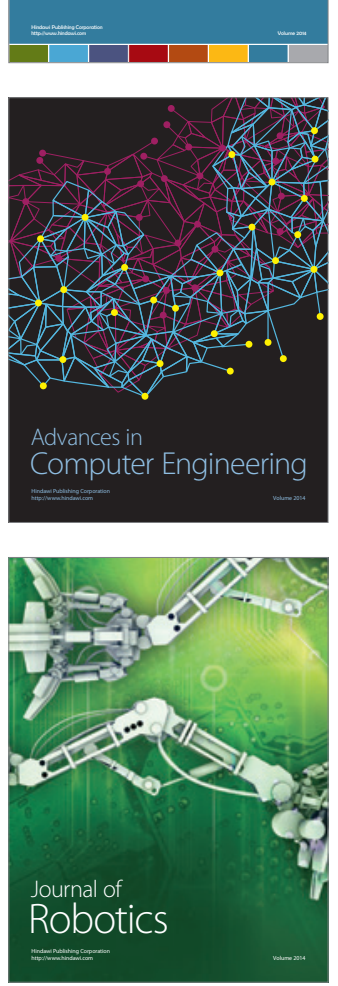
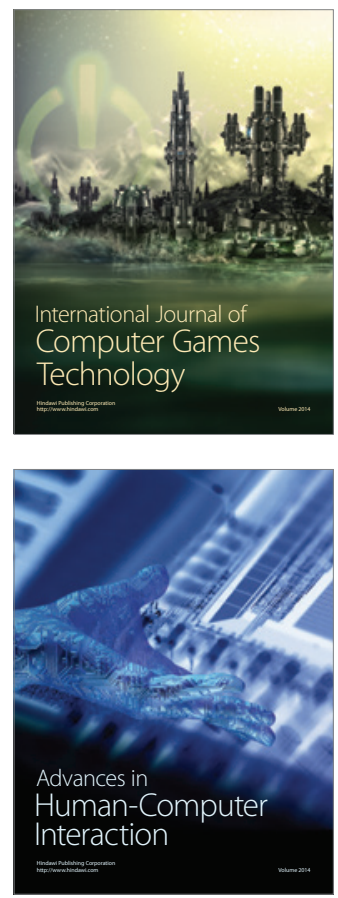
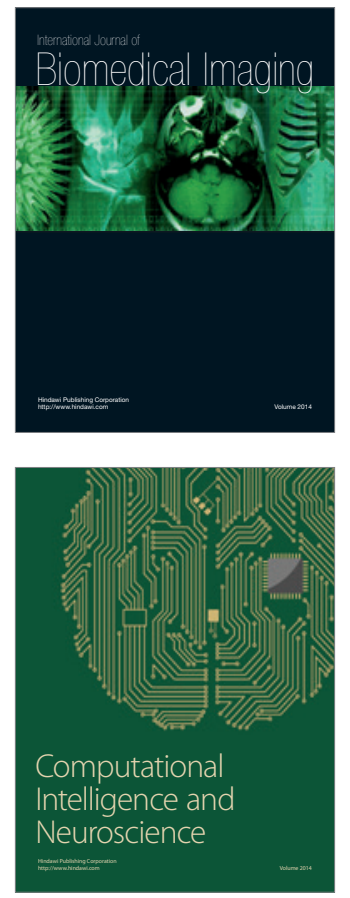
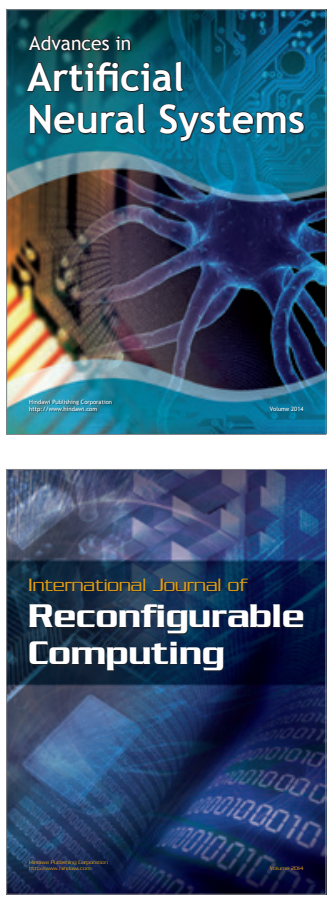
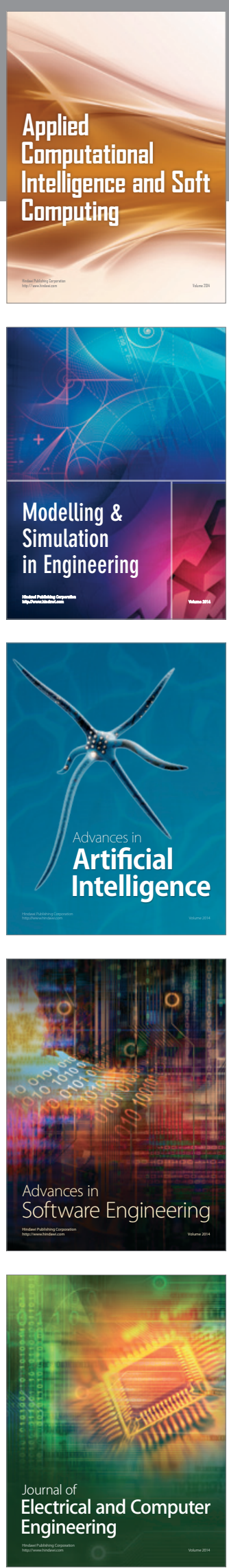